\title{
Los Pedroches: una comarca cordobesa en busca de sus raíces
}

La configuración del Estado Español en Autonomías, generó una gran vehemencia en la búsqueda de la propia historia, de cada una de ellas. Prueba de ello, ahí están, las grandes enciclopedias editadas con rapidez, para recoger los personajes y datos más importantes.

Luego llegó la hora de la comarcalización y esa misma actitud de encontrar las propias señas de identidad, llegó a los ciudadanos de a pie, dispersos por los pueblos. Se suscitaron multitud de colectivos con esta finalidad, en todos los aspectos que componen la vida humana. Unos sucumbieron con la misma rapidez con que habían nacido, pero otros persisten en su tarea, cada vez más concienciados y más activos.

Tal es el caso de la Asociación "Piedra y Cal" de Pozoblanco, nacida precisamente para defensa del Patrimonio Histórico.

Durante estos años ha trabajado bien y mucho. Ha levantado la voz en alguna ocasión haciéndose oír y ha cultivado a sus miembros, realizando excursiones culturales.

Esta asociación, nacida con vocación comarcal. ha organizado, con el apoyo de la Fundación, Ricardo Delgado Vizcaíno, las I Jornadas sobre Patrimonio en la Comarca de Los Pedroches., durante los días 8,9 y 10 de marzo de 200I, en el Auditorio del Recinto Ferial de Pozoblanco

Hicieron la presentación de las Jornadas, Tomás Aránguez, presidente de la fundación "Ricardo Delgado Vizcaino", el presidente de la Asociación "Piedra y Cal", Valerio Moreno y el concejal de Cultura del Ayuntamiento de Pozoblanco, Serafín Pedraza.

Gracias al apoyo recibido, pudo invitar a figuras de primera línea en estas lides, como son los profesores Isidoro Navarro Moreno, y Juan Agudo Torrico del Departamento de Antropología Social de la Universidad de Sevilla y Francisco Esojo Aguilar, de la Asociación Provincial de Museos Locales.

Isidoro Moreno Navarro desarrolló de manera magistral, llegando al gran publico asistente, la relación del Patrimonio con la propia identidad. Habló de los peligros que se ciernen como son la globalización, la epidemia del olvido, para invitar a los asistentes a una reapropiación de todo lo que constituyen sus propias señas de identidad.
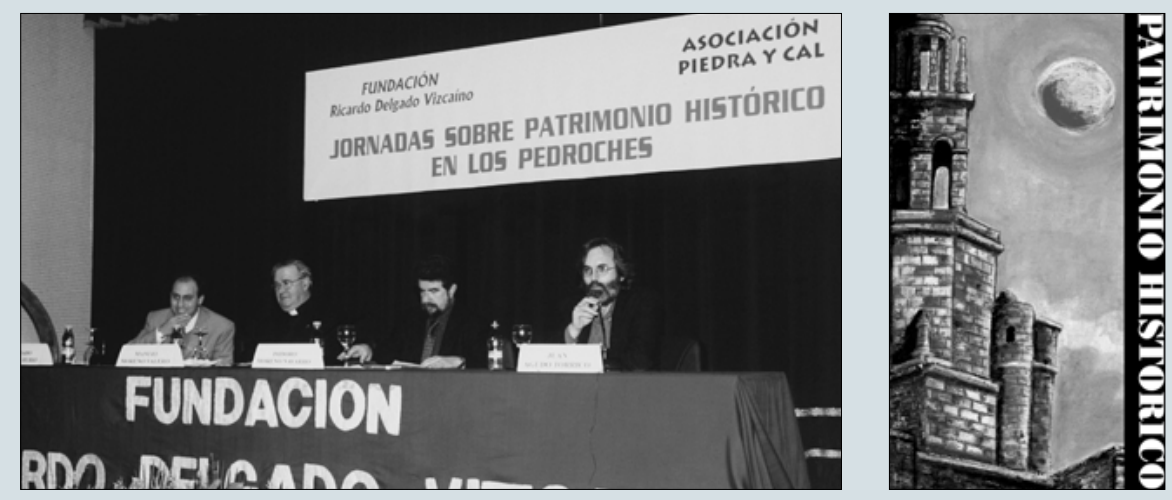

Juan Agudo Torrico, natural de la comarca y gran conocedor de la vivienda tradicional de Los Pedroches, disertó sobre el tema con gran profusión de diapositivas sobre el uso de los medios propios, como es la piedra de granito, así como la configuración y distribución de la vivienda.

Francisco Esojo, a través de su intervención, dio a conocer las finalidades y actividades de la Asociación Provincial de Museos Locales, engrandeciendo la labor que desarrollan en la formación de las entidades que tienen como misión proteger el Patrimonio.

El objetivo de las Jornadas quedaba marcado en el cartel anunciador de las mismas: la emblemática torre de Pedroche entre la luna y el sol. Un antes y un después. Salida del obscurantismo y del olvido de la riqueza patrimonial, para adentrarnos en una luminosidad espléndida y radiante, que hace desaparecer la noche en que hasta ahora se ha vivido en esta comarca.

Finalizadas estas Jornadas, su balance ha sido muy positivo. Han tenido un éxito enorme de asistencia, de personas cualificadas, de maestros y profesores de instituto, así como profesionales liberales. Esto es índice del interés que habían suscitado y de la esperanza que engendran para el futuro, todo lo que lleve a la concienciación de la ciudadanía, como garante de la conservación de su Patrimonio.

Las ponencias fueron seguidas de comunicaciones que complementaron y enriquecieron aún más lo ya escuchado. Las comunicaciones presentadas pretendían aterrizar en lo concreto de la situación de Los Pedroches, lo que se había desarrollado en las ponencias. Intervinieron Manuel Moreno Valero, Cronista Oficial de Pozoblanco, Conrado Castilla, profesor de instituto, José Luis Amor Trucios, arquitecto,
Antonio Fermín Morillo, profesor de instituto, Esteban Márquez, Cronista Oficial de Torrecampo, Eloy Moreno y Elodia Hernández, del Instituto Andaluz de Patrimonio.

El colofón lo puso la mesa redonda, moderada por el vicepresidente de la asociación "Piedra y Cal" José María Fernández, donde hubo debates y se tomaron posiciones y actuaciones para el futuro. Finalizaron las Jornadas con un viaje cultural a Pedroche y Torrecampo.

Como actividad complementaria, durante esos días, se montó una exposición etnológica en la Casa del Pozo Viejo. Dicha exposición realizada gracias a la colaboración de Bartolomé Moreno de Gracia, ha sido muy visitada y admirada, no solo por los vecinos de Pozoblanco, sino de toda la comarca. Abundaron las visitas concertadas de colegios e institutos de la comarca y otras colindantes y para guiar dichas visitas, los miembros de Piedra y Cal se pusieron a disposición de manera generosa. Para muchos, esta visita, suponía un anticipo de lo que sueñan desde hace muchos años: Museo Etnológico de la Comarca de Los Pedroches.

La Asociación "Piedra y Cal", ha pretendido meter en la cabeza y en el corazón de todos los pedrocheños el amor e interés por todo lo que constituye su Patrimonio y para ello ha querido mentalizarlos en la relación, que el Patrimonio tiene con su propia identidad. Buscar su significado y simbolismo, será tarea a desarrollar, para que todos seamos albaceas del valioso legado que hemos recibido, y por tanto a todos nos incumbe el deber de salvaguardarlo, conservarlo y enriquecerlo, para disfrute de generaciones venideras. Cronista Oficial de Pozoblanco 